\title{
Pollutants site ratio as appointment of highway, industrial and farming sources
}

\author{
L. Bontempi ${ }^{1}$, M. L. Ruello ${ }^{2} \&$ G. Fava ${ }^{2}$ \\ ${ }^{1}$ Tecnica Bontempi snc, Italy \\ ${ }^{2}$ Department of Materials and Environmental Engineering and Physics, \\ Università Politecnica delle Marche, Italy
}

\begin{abstract}
An in-situ field study was conducted to measure the outdoor pollutant concentrations necessary to design the ventilation-filtration system and improve the indoor air quality of a public building. The area of study is located in the flat terrain of the Italian Po valley, near a traffic-congested highway and surrounded by an industrial factory and many farms. The quality of the ambient air was evaluated monitoring $\mathrm{NO}_{2}$, toluene and xylenes concentrations, and was compared with that in urban atmospheres and related to traffic emissions. Measurements of pollutant were performed with passive diffusion samplers with the aim to test the hypothesis that the highway contribution to ambient air quality varies with the logarithm of the distance. The toluene/xylenes ratio measured at the building site and at the highway source ratio suggested that beside vehicular emission, industrial and farming sources were governing the volatile organic compounds in the area. The present study confirmed that $\mathrm{NO}_{2}$ concentration at a nearby highway varied linearly with the logarithm of the distance from the highway, but the slope found for this regression was somewhat steeper than those reported in the literature for urban conditions. The reason for this has not been related to augmented atmospheric dispersion differences. Instead, the presence of hydroxyl radicals and volatile organic compounds of either agricultural or industrial origin may affect a complex ozone-hydrocarbon reactivity. The results delineate the pollutant site ratio and the traffic equivalent distance as useful parameters for the source emissions characterisation and the selection of an effective control technology.

Keywords: traffic emissions, environmental profiles, source emission ratio, equivalent distance, V.O.C. reaction kinetic.
\end{abstract}




\section{Introduction}

In the context of a study on highway emissions facing a residential area under construction, a series of gradient measurements of $\mathrm{NO}_{2}, \mathrm{SO}_{2}, \mathrm{O}_{3}$ and VOC concentrations with increasing distance from the highway were performed using passive diffusion samplers. In recent papers results showing a logarithmic relationship between $\mathrm{NO}_{2}$ concentration and distance from the highway have been presented [1-3]. Such relationship can be useful in outdoor-indoor air quality relationship, when the distance to major roads is sometimes used to estimate pollution level, and the degree of air purification needed to obtain the desired indoor air quality is required. It is however essential to test the general validity of these relationships using data from different geographical areas and also to extend the research to other traffic related volatiles pollutants like benzene, toluene and xylenes and other aromatic hydrocarbons. The small-scale spatial variability of air pollution observed in urban areas has often created concern about the representativeness of measurements used in exposure studies for risk assessment. In the literature there are a relatively high number of articles published on the concentration of some of the important urban pollutants and the main anthropogenic sources. However most of the studies have been focused on the determination of their absolute concentrations with hot-spot samplings. More valuable information can be gained from measurements in which the time weighted average (TWA) concentrations are determined because these are much less susceptible to instantaneous variations of local conditions. Diffusive sampling then becomes an ideal method to determine concentrations for prolonged sampling times because of the possibilities of unattended operations, ease of handling and an overall low-cost [4]. Although TWA concentrations are more significant in terms of atmospheric modelling, the relative ratio of TWA concentrations of certain compounds can be even more useful. While absolute concentrations are affected by vertical mixing and other atmospheric processes, the relative ratios are solely dependent on differences in the mechanism and rates of photochemical reactions provided that the compounds are emitted from the same sources at nearly constant emission ratio. Aromatic hydrocarbons are ideal candidates for such studies, as they are reactive in the atmosphere, have life times of several hours and, in addition, they can be diffusively sampled. Two of the most abundant aromatic hydrocarbons, toluene and xylenes, are especially worth studying, as there are quite significant differences between their reactivity (toluene is five times and xylenes nineteen times as reactive as benzene in their reactions with $\mathrm{OH}$ radicals [5-8]). In this study the relative concentration ratio of toluene and xylenes was used to determine the similarity as "distance" of the sampling site from traffic-originated emission sources, assuming that transport was the predominant source of these compounds. This is a problem of topical interest since for NMHCs the conventional distinction between "urban", "industrial" and "rural" sites can hardly be supported any longer: the traffic accounting for $70 \%$ of the emissions cannot be localized to the downtown of the cities as a dense network of busy highways covers the countryside [9]. 
An area located in the proximity of the Italian Highway A1, and characterized by intensive farming as well as some petrochemical activity were investigated, in order to study the relationship between the distance from the highway and to aid the selection of an effective strategy for maintain a good indoor air quality.

\section{Site description}

The area selected for the measurements, located near Highway A1, close to the Italian town of Lodi, is characterised by a flat ground and the presence of a number of dairies and feedlots. Schematic representation of the area and sites chosen for measurements are shown in Figures 1 and 2. The traffic flow on the highway was estimated by counting the numbers of cars and heavy trucks passing by in a random 5 min periods during the daily measurements. The diurnal average traffic densities during the measurements were 2500-5000 vehicles per hour, around $35 \%$ of which were trucks.

\section{Experimental results and discussion}

Measurements were made at distances of $10 \mathrm{~m}, 30 \mathrm{~m}, 70 \mathrm{~m}, 750 \mathrm{~m}$, respectively from the fence of the highway. Figure 2 shows the sampling layout. The closest point to the source (at $10 \mathrm{~m}$ ) was used as a reference point. Air samples, contaminated by traffic and possibly by other sources of emissions, were collected by means of an active and passive sampling. Radiello ${ }^{@}$ axial diffusive tubes filled with Carbotrap-B and with a solid sorbent doped with Triethanolamine were continuously exposed for ten to fifteen days. VOC were analysed in the laboratory using gas chromatography (column type: Ultra1 $30 \mathrm{~m} \times 0.32 \mathrm{~mm} \times 0.52 \mu \mathrm{m})+$ FID. Main inorganic ions were collected by extraction with deionised water and analysed by liquid chromatography.

In Figure 3 the concentrations of $\mathrm{NO}_{2}$, representative of summer and autumn time intervals, are plotted against the logarithm of the distance from highway. The measurements show a strong correlation between the $\mathrm{NO}_{2}$ concentration, $\mathrm{C}(\mathrm{x})$, and the logarithm of the distance in metres from the highway. The following model was assumed to apply in the vicinity of the road: $\mathrm{C}(\mathrm{x})=\mathrm{C}_{\mathrm{b}}+\mathrm{C}_{0}-\mathrm{k}^{*} \log (\mathrm{x})$, where $\mathrm{C}(\mathrm{x})$ is the concentration at distance $\mathrm{x}(\mathrm{m})$ from the highway, $\mathrm{C}_{\mathrm{b}}$ is the general background concentration of $\mathrm{NO}_{2}, \mathrm{C}_{0}$ is the concentration contributed by the high road at $\mathrm{x}=0$ and $\mathrm{k}$ is a constant. A point $10 \mathrm{~m}$ far from the highroad, was used as the highway source emission and used as reference point to calculate relative site concentrations as $\mathrm{C}_{\mathrm{rel}}=\left(\mathrm{C}_{\mathrm{x}}-\mathrm{C}_{\mathrm{b}}\right) / \mathrm{C}_{\mathrm{ref}}$. This transformation is introduced to obtain a relationship between the relative concentration and the logarithm of the distance from the highroad: $\mathrm{C}_{(\mathrm{rel})}=\left(\mathrm{C}_{0^{-}}\right.$ $\mathrm{K} * \log (\mathrm{x}))^{*} 1 / \mathrm{C}_{\mathrm{ref}}$. The resulting regressions compared in Figure 4 , show that the slope obtained during summer and autumn typical whether conditions are similar but somewhat steeper than that reported in literature. Hence the indications from the present study substantially support the result obtained by Gilbert et al. [1] that the $\mathrm{NO}_{2}$ concentration nearby a highway can be assumed to vary linearly with the logarithm of the distance from the highway. The slope of the regression 
line has been previously related to differences in the roughness of the landscape, wind speed and atmospheric stability. However the agricultural landscape characterizing the location under investigation had a very low-roughness, not likely to explain the steeper gradient and also the more stable atmospheric stability characterizing autumn whether can not be called to account for. A different approach, based on a toluene-xylenes ratio as a tool to characterize the local emission sources was then considered. First, the relative toluene to xylenes concentration ratio, expressed in $\mu \mathrm{g} / \mathrm{m}^{3}$, was determined at the reference site (herein after referred to as "highway emission ratio") using TWA concentrations (ten to fifteen days sampling time) to minimize the effects of changes due to local factors. The ratio of the TWA concentrations of these compounds was also measured at different sampling sites (hereinafter referred to as "site ratio"). Knowing these values, the rate constants and mechanism of predominant photochemical processes, it is then possible to calculate the time required for the transformation of the source emission ratio into the site ratio. The parameter thus obtained can also be used to characterize a "distance" of the sampling site from traffic-originated emission sources.

\section{Degradation mechanisms for toluene and xylenes}

Toluene and xylenes, as monoaromatic hydrocarbons react very slowly with ozone and $\mathrm{NO}_{3}$ radicals, their rate constants being of the order of $<10^{-20}$ and $<10^{-16} \mathrm{~cm}^{3} *$ molecule $\mathrm{s}^{-1}$, respectively. Thus their depletion in the atmosphere via these reactions is negligible. The only significant process for the atmospheric loss of these compounds is their photochemical reaction with $\mathrm{OH}$ radicals, having rate constants $5.96 * 10^{-12}$ and $2.36 * 10^{-11} \mathrm{~cm}^{3} *$ molecule ${ }^{-1} \mathrm{~s}^{-1}$ for toluene and xylenes, respectively.

The average daily concentration of $\mathrm{OH}$ radicals on the northern hemisphere at mid-latitudes, near ground level, according to a recent study, is $2 * 10^{6}$ molecule $\mathrm{cm}^{-3}$ during summer and $0.8^{*} 10^{6}$ molecule* $\mathrm{cm}^{-3}$ during autumn [9]. Having determined the "highway emission ratio", subsequent calculations can be performed: the concentration of toluene is reduced by the reaction with $\mathrm{OH}$ radicals as well as by air mixing.

If $\mathrm{C}(\mathrm{s})$ is the time-weighted average concentration of toluene and xylenes respectively at the sampling site in $\mu \mathrm{g} / \mathrm{m}^{3}, \mathrm{C}(\mathrm{e})$ the time-weighted average concentration as determined in the reference site,

$$
C\left(i_{s}\right)=f(t) \cdot C\left(i_{e}\right) \cdot e^{K(i) \cdot C(O H) \cdot t}
$$

where $f(\mathrm{t})$ is the time-dependent mixing factor, $K(i)$ is the rate of reaction of the compound (i) with $\mathrm{OH}$ radicals, $\mathrm{C}(\mathrm{OH})$ is the average daylight concentration of $\mathrm{OH}$ radicals at the sampling site during the sampling period in molecule $/ \mathrm{cm}^{3}$, and $t$ the time in seconds. Introducing the terms $\mathrm{C}_{\text {Toluene }} / \mathrm{C}_{\text {Xylenes }}$, " $r_{s}$, site ratio" and " $r_{e}$, reference highway emission ratio", $r_{S=} \mathrm{C}_{(\mathrm{T})} / \mathrm{C}_{(\mathrm{X})}$, at the site ratio, and $r_{e}=\mathrm{C}_{(\mathrm{T})} / \mathrm{C}_{(\mathrm{X})}$, at the source emission ratio can be obtained. 
Finally, expression of

$$
t=\frac{\ln \left(r_{s} / r_{e}\right)}{\left(k_{x}-k_{t}\right) \cdot C(O H)}
$$

yields the time $t$, which may be termed the "traffic-equivalent distance". On the basis of the above calculations, the traffic-equivalent distance may be defined as the number of daylight hours required to convert the source emission ratio into the site ratio assuming steady-state $\mathrm{OH}$ radical concentration. This parameter may be used to characterize the "distance" of the sampling site from trafficoriginated emission sources. The values obtained are reported on Figures 5 and 6 and summarized in Tables 1 and 2.

Table 1: $\quad$ Site distance from the highway, TWA concentrations of toluene and xylenes, calculated site ratio and calculated source equivalent distances (in hours) during summer atmospheric conditions.

\begin{tabular}{|c|c|c|c|c|}
\hline $\begin{array}{c}\text { Site } \\
\text { (distance } \mathrm{m})\end{array}$ & $\begin{array}{c}\mathrm{C}_{\text {Toluene }} \\
\mu \mathrm{g} / \mathrm{m}^{3}\end{array}$ & $\begin{array}{c}\mathrm{C}_{\text {Xylenes }} \\
\mu \mathrm{g} / \mathrm{m}^{3}\end{array}$ & $\begin{array}{c}\text { Site ratio } \\
\mathrm{C}(\mathrm{T}) / \mathrm{C}(\mathrm{X})\end{array}$ & $\begin{array}{c}\text { Traffic equivalent } \\
\text { distance }(\mathrm{h})\end{array}$ \\
\hline $1(10)$ & 36 & 24 & 1.50 & 0 \\
\hline $2(30)$ & 31 & 16 & 1.95 & 2.07 \\
\hline $3(70)$ & 28 & 13 & 2.15 & 2.93 \\
\hline $4(750)$ & 21 & 9 & 2.33 & 3.57 \\
\hline
\end{tabular}

Table 2: $\quad$ Site distance from the highway, TWA concentrations of toluene and xylenes, calculated site ratio and calculated source equivalent distances (in hours) during autumn atmospheric conditions.

\begin{tabular}{|c|c|c|c|c|}
\hline $\begin{array}{c}\text { Site } \\
\text { (distance } \mathrm{m})\end{array}$ & $\begin{array}{c}\mathrm{C}_{\text {Toluene }} \\
\mu \mathrm{g} / \mathrm{m}^{3}\end{array}$ & $\begin{array}{c}\mathrm{C}_{\text {Xylenes }} \\
\mu \mathrm{g} / \mathrm{m}^{3}\end{array}$ & $\begin{array}{c}\text { Site ratio } \\
\mathrm{C}(\mathrm{T}) / \mathrm{C}(\mathrm{X})\end{array}$ & $\begin{array}{c}\text { Traffic } \\
\text { equivalent } \\
\text { distance }(\mathrm{h})\end{array}$ \\
\hline $1(10)$ & 6 & 3.3 & 1.8 & 0 \\
\hline $2(30)$ & 5 & 2.5 & 2.0 & 2.77 \\
\hline $3(70)$ & 4 & 1.9 & 2.1 & 4.05 \\
\hline $4(750)$ & 3 & 1.6 & 1.9 & 1.42 \\
\hline
\end{tabular}

As can be seen from the data of Table 1, in summer, the absolute concentrations of toluene decrease when moving from the highway location (Site 1) to less polluted background areas (Site 4). If, however, the concentrations of xylenes are compared, the decrease is much more pronounced. However, the absolute concentrations are largely dependent on many factors which are not possible to account, hence their site ratio was considered. The value of 1.50 characterizing the Site 1 is close to that found for urban locations 
(1.36 s.d 0.37 for 7 roadside urban microenvironments sites), while this parameter for remote areas is close to one [10-12]. The difference found in the background rural area (Site 4, ratio 2.33), suggests that in the area others sources of aromatic hydrocarbons do exist (as is typical for a refinery or a chemical cracking plant), and their contribution are superimposed upon the traffic emissions.

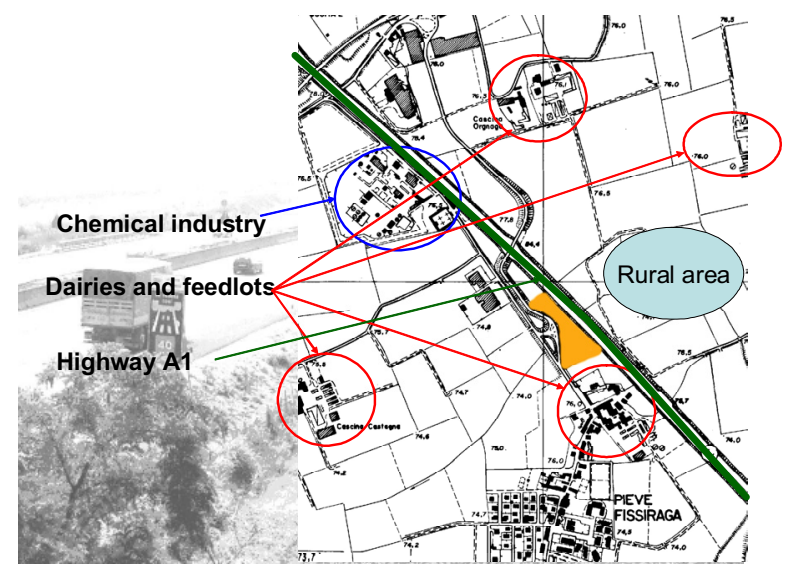

Figure 1: Spatial site characteristics.

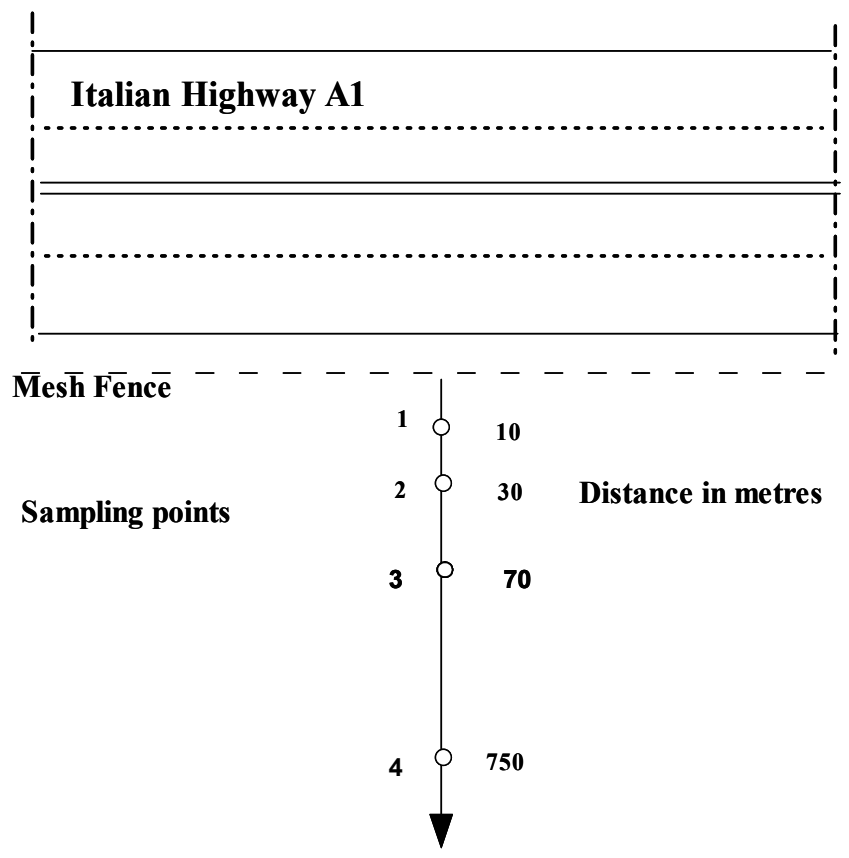

Figure 2: $\quad$ Distance from the road and the sampling points (metres). 


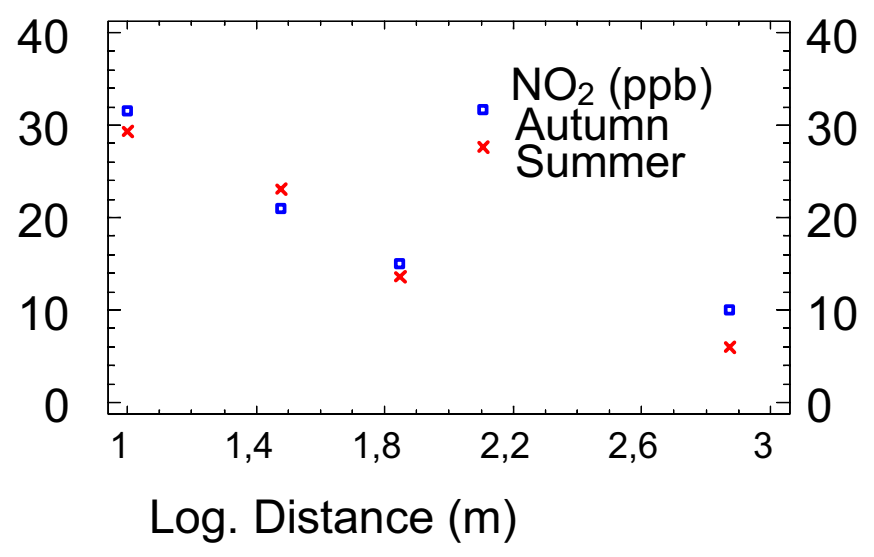

Figure 3: Relationship between concentration of $\mathrm{NO}_{2}(\mathrm{Cx}, \mathrm{ppb})$ and the logarithm of the distance (m) from the highway.

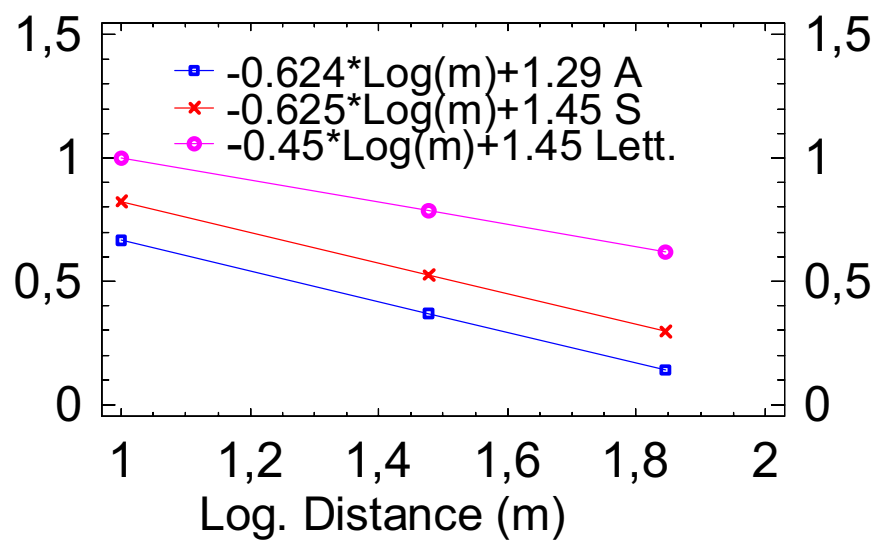

Figure 4: Relationships between the relative concentration (Crel) and the logarithm of the distance (m) from the highway.

The difference is also manifest for the traffic-equivalent distance (TED). Assuming the highway as the emission source, the time distance becomes higher with the distance from the highway (Tables 1 and 2). Interesting appears the autumn situation, when, while the concentrations are significantly lower than those found in summer, the calculated site ratio and traffic-equivalent distance $(2-4 \mathrm{~h})$ are similar except for the more distant site $(750 \mathrm{~m})$ (Figure 6). These results point out that the distance of the emission sources does not change, but their intensity does. Only in the autumn at the Site 4 , both the toluene/xylene site 
ratio and TED appear changed again implying that local additional sources, different from traffic must be accounted for.

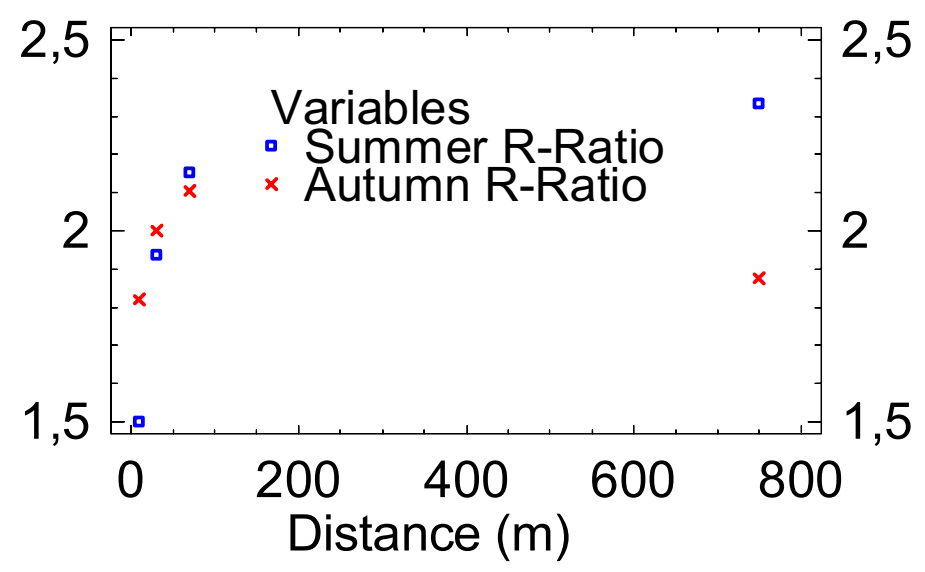

Figure 5: Calculated site ratio for toluene and xylenes during summer and autumn atmospheric conditions.

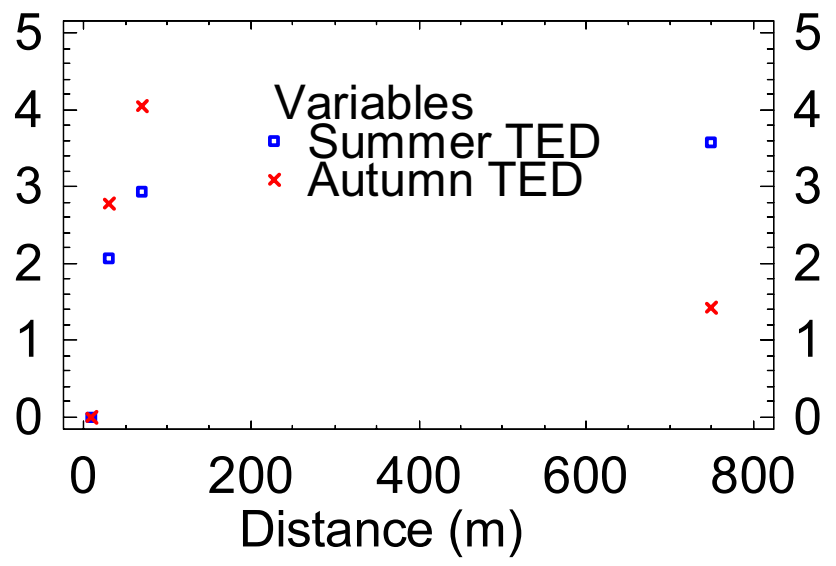

Figure 6: Calculated traffic-equivalent distance (h) for summer and autumn conditions.

\section{Conclusions}

The purposes of this study were to evaluate the applicability of a traffic emission reference based on $\mathrm{NO}_{2}$ gradient and to apply the proposed method to assess traffic contribution to individual hydrocarbons in a rural agricultural area 
characterized by the presence of a busy highway. The present study confirmed that $\mathrm{NO}_{2}$ concentration nearby a highway varies linearly with the logarithm of the distance from the highway, but the slope found for this regression was somewhat steeper than those reported in the literature for urban conditions. The relationship between $\mathrm{NO}_{2}$ concentration and the distance from the highway cannot be assumed to be representative of more unreactive species in traffic exhausts, but can be an useful index for certain types of technological deployment as building ventilation and indoor air quality evaluation. In accordance with literature, the results of the present investigation point to a downwind distance of about $300 \mathrm{~m}$ to eliminate measurable influence of a highway on the $\mathrm{NO}_{2}$ concentration. The average concentrations of VOCs like toluene and xylenes in the study area were similar to those measured in urban areas without major industrial sources. This finding was somewhat unexpected because the study area was not affected by general urban emissions being a typical agricultural area. The results show that some chemical species, such as toluene or xylenes, are emitted from non-traffic sources and were significant during the two sampling periods. By comparing the toluene/xylenes ratios observed in the area with traffic reference values, one can quickly diagnose the significance of non-traffic emissions lending to the selection on an effective control technology and planning to enhance indoor air quality.

It can then be concluded that the site ratio and traffic-equivalent distance parameters are more useful for the characterization of a given site with respect to the proximity of vehicular emission sources than the absolute concentrations of some selected pollutants.

\section{References}

[1] Gilbert, N.L, Woodhouse, S., Stieb, D.M. \& Brook, J.R., Ambient nitrogen dioxide and distance from a major highway. Sci. Total Environ. 2003, 312, 43-6.

[2] Rodes, C.E. \& Holland, D.M., Variations of $\mathrm{NO}, \mathrm{NO} 2$ and $\mathrm{O} 3$ concentrations downwind of a Los Angeles freeway. Atmos. Environ. 1981, 15, 243-50.

[3] Roorda-Knape, M.C., Janssen, N.A.H., de Hartog, J., van Vliet, P.H.N., Harssema, H. \& Brunekreef, B., Traffic related air pollution in city districts near motorways. Sci. Total Environ. 1999, 235:339-41.

[4] Ferm, M. \& Svandberg, P.A., Cost-efficient techniques for urban- and background measurements of SO2 and NO2. Atmos. Environ. 1998;32:1377-81.

[5] Atkinson, R., Plum, C. N., Carter, W. P. L., Winer, A. M. \& Pitts, J. N. Jr., Rate constants for the gas phase reactions of NO3 radicals with a series of organics in air. J. Phys. Chem., 1984, 88, 1210.

[6] Atkinson, R., Atmospheric chemistry of VOC and NOx. Atmos. Environ. 2000; 34: 2063-2101

[7] Carter, W.P. \& Atkinson, R., Computer Modeling Study of Incremental Hydrocarbon Reactivity. Environ. Sci. Technol. 1989, 23, 864-880 
[8] Carter, W. P. L., Development of ozone reactivity scales for volatile organic compounds. J. Air Waste Manag. Assoc., 1994, 44, 881-899.

[9] Gelencser, A., Siszler, K. \& Hlavay, J., Toluene-benzene concentration ratio as a tool for characterizing the distance from vehicular emission sources. Environ. Sci. Technol., 1997, 31, 2869-2872.

[10] McLaren, R., Gertlera, W., Wittorff, D.N., Belzer, W., Dann, T. \& Singleton D.L., Real-world Measurements of Exhaust and Evaporative Emissions in the Cassiar Tunnel Predicted by Chemical Mass Balance Modeling. Environ. Sci. Technol. 1996, 30, 3001-3009.

[11] Chan, C.Y., Chan, L.Y., Wang, X.M., Liu, Y.M., Lee, S.C., Sheng, G.Y. \& Fu, J.M., Volatile Organic Compounds in Roadside Microenvironments of Metropolitan Hong Kong. Atmos. Environ. 2002, 36, 2039-2047.

[12] Hwa, M.Y., Hsieh, C.C., Wu, T.C. \& Chang, L.F. Real-world Vehicle Emissions and VOC Profile in the Taipei Tunnel Located at Taiwan Taipei Area. Atmos. Environ. 2002, 36, 1993-2002 